\title{
Comparative Study between Supracutaneous Plate and Minimally Invasive Plate Osteosynthesis in Distal Tibia Fracture
}

G.E.Kazem, H.E.Faraj, E.A.Tabl and M.M.Hussein

Orthopedic Surgery Dept., Faculty of Medicine, Benha Univ., Benha, Egypt

E-Mail:Montaser@gmail.com

\begin{abstract}
Tibial fractures are the most common fracture of long bones. These wounds result from highvitality injury, for example, tumble from tallness and vehicle accidents.Management of distal tibia breaks, with or without articular association, is a restorative test. Numerous osteosynthesis procedures can be utilized for these breaks and these methods have favorable circumstances and disservices and there is no agreement concerning the administration of these cracks. Randomized forthcoming examination included 40 patients with distal third extra-articular tibia shaft cracks (20 rewarded with supracutaneous - LCP and 20 with MIPO plate), were chosen dependent on the break example and grouped utilizing the $\mathrm{AO}$ characterization (AO/OTA types $43 \mathrm{~A}$ and distal $42 \mathrm{~A}-\mathrm{C}$ as it were). Gathering I, $15 \%$ of patients accomplished relationship between $20-24$ weeks, $70 \%$ of patients accomplished joining between 17-20 weeks and 15\% of patients accomplished association $\leq$ four months. In Group II, $5 \%$ of patients accomplished association $\geq 24$ weeks, $10 \%$ of patients accomplished relationship between 20-24 weeks and $40 \%$ of patients accomplished joining between $17-20$ weeks and in $45 \%$ of patients association took $\leq$ four months. The Lower Extremity Functional Scale is $74.87 \%$ in supracutaneous plate bunch 1 with mean $(60.3 \pm 4.87)$. Furthermore, $75.93 \%$ in Mipo bunch 11 with mean (60.3 \pm 4.87 ). with no measurably noteworthiness, (P. esteem is 0.481 ). This examination results show a predominance of supracutaneous plate over MIPO method as far as expelled after association with most straightforward expulsion, lower paces of profound contaminations and shorter opportunity to full weight bearing. Though MIPO procedure gave off an impression of being profitable over supracutaneous plate as far as prompting a superior anatomical and fixed decreases of the crack, a fast and straight forward application, has a diminished careful time and a lower pace of association difficulties.
\end{abstract}

\section{Introduction}

The treatment of cracks of the distal piece of the lower Leg is trying for orthopedic specialists and regularly prompts genuine inconveniences, for example, contamination, malunion, nonunion and post-horrendous joint pain. The distributed outcomes are frequently hard to think about in light of critical heterogeneity of bone and delicate tissue wounds [1].

The subcutaneous and generally uncovered situation of the metaphysis (to be sure, delicate tissues are extremely meager in this area of the leg), implies that cracks in the distal tibia metaphysis, in any event, following low-vitality injury, ordinarily have more serious delicate tissue injury than revealed for breaks of the tibial diaphysis, besides, tibial distal breaks are much more in danger of introduction in view of their vicinity to the lower leg and the absence of blood vessel flexibly in the distal tibia $[2,3]$.

Along these lines, the distal metaphysis is particular from the diaphysis and a different audit of careful mediations for rewarding distal tibia metaphyseal cracks is justified [4].

The objective of orthopedic specialists is to reestablish the tibial life systems, to fix the epi-metaphyseal obstruct with the diaphysis and to maintain a strategic distance from inconveniences [4].
Once in a while, two treatment techniques might be utilized in mix; for instance, nailing joined with plating $[5,6]$.

Until this point in time, bolted plates, intramedullary nails and outer obsession are the three most utilized methods, yet each has been truly identified with inconveniences: malalignment and knee torment have been related with nailing; contaminations, wound intricacies and embed unmistakable quality are every now and again detailed after tibial plating; delayed crack mending, visit need of auxiliary activities and diseases of the pin lot are intrinsic in outside obsession $[7,8]$.

Numerous osteosynthesis methods can be utilized for these breaks, for example, customary open decrease and interior obsession (ORIF), outer obsession with or without constrained inward obsession, intramedullary nailing or, all the more as of late, insignificantly intrusive plate osteosynthesis (MIPO) [9, 10]. All of these strategies have favorable circumstances and disservices and there is no agreement concerning the administration of these cracks. $[11,12]$.

In spite of progress of surgeries, results are not generally brilliant and intricacies influence 20-half of patients [13].

The principle point of the investigation is to look at the utilitarian recuperation of the patients who had distal extra articular crack 
rewarded with supracutaneous - LCP and insignificantly obtrusive plate osteosynthesis (MIPO).

\section{Patient and method}

This randomized prospective study included 40 patients with distal third extraarticular tibia shaft fractures $(20$ treated with supracutaneous -LCP and 20 with MIPO plate), were selected based on the fracture pattern and classified using the AO classification (AO/OTA types 43A \& distal 42A-C only)

Inclusion criteria was Patients having fracture of distal tibia with Extra articular fracture, of the distal tibial metaphysis, metadiaphyseal junction and adjacent diaphysis of Skeletally mature patient (Age above $18 \mathrm{yrs}$ and less than $60 \mathrm{yr}$ old) and with closed and open fracture gustilo Anderson type 1 and type2. Exclusion criteria was Intraarticular fracture, type 3 compound fractures of distal tibia and Pathological fractures.

Our protocol in management of distal tibia fracture consists of immediate reduction with temporary plaster stabilization. Soft tissue assessment is performed prior to surgery.

Each patient was assigned a random number at administration, and then include in group I (treated with the supracutaneous -LCP) or group II (fixed with the MIPO) according to the random number table.

An associated fibula fracture can be treated with ORIF if the soft tissue allows it. Elevation of the fractured limb with generous use of ice to reduce the swelling are utilized in the initial management. Open injuries treated with intravenous antibiotics, adequate wound debridement and lavage prior to any definitive fixation.

We scheduled clinical, functional, and radiographic (plain anteroposterior and lateral radiographs) evaluations after surgery at 2, 4, 12, 24 weeks, as possible. Fractures were considered healed when mature bridging callus was identified on two views and patients reported no pain on full weight bearing, and if doughty about union CT scan would be conduct. Outcome parameters included occurrence of complications (the union rate, deformity, and infections and other complications) and functional recovery of the patients using Lower Extremity Functional Scale (LEFS).

\section{Results}

As indicated by AO-arrangement ofdistal-tibial-crack (43A sort) There were 10 patient with a 43A1 break, 7 patient with a $43 \mathrm{~A} 2$ break, and 3 patient with a $43 \mathrm{~A} 3$ crack in bunch 1 . In bunch 11, there were 7 patient with a 43A1 break, 9 patient with a 43A2 crack, and 4 patient with a $43 \mathrm{~A} 3$ crack Fig (4).

In bunch 1, six patients had open crack (four Gustilo type one and two Gustilo type two). In bunch 1l, two patients had open break Gustilo type one Fig (5).

In this investigation in Group I, $15 \%$ of patients accomplished relationship between 2024 weeks, $70 \%$ of patients accomplished joining between 17-20 weeks and $15 \%$ of patients accomplished association $\leq$ four months. In Group II, 5\% of patients accomplished association $\geq 24$ weeks, $10 \%$ of patients accomplished joining between 20-24 weeks and $40 \%$ of patients accomplished relationship between 17-20 weeks and in 45\% of patients association took $\leq$ four months Fig (3).

In bunch 1; five patients had pin track disease, and one of them had late profound contamination (releasing sinus from injury of open crack), (5\% profound disease and absolute 30\%). In bunch 11; three patients had shallow contamination, and two patients had profound diseases, them two were Gustilo Open (10\% profound disease and totaln $25 \%$ ) Table (2)

We utilized the Lower Extremity Function Scale (LEFS), to analyze the practical result between the two gatherings. LEFS is expected to survey useful status in patients with inability of the lower furthest point, the patient reacts to questions that help decide the level of trouble the patient encounters with 20 ordinary exercises. In bunch 1, the range was (53 - 70), with mean $(60.3 \pm 4.87)$. In bunch 11 , the range was $(60.3 \pm 4.87)$ with mean $(60.3 \pm 4.87)$.there were no factually essentialness, (P. esteem is 0.481) Table (1).

Table (1) Demographic data of LEFS test.

\begin{tabular}{lccc}
\hline & $\begin{array}{c}\text { Supracutenious } \\
\text { plate }(\mathbf{n = 2 0})\end{array}$ & $\begin{array}{c}\text { MIPO Plating } \\
(\mathbf{n = 2 0})\end{array}$ & P. value \\
\hline LEFS & $53-70$ & & \\
Range & $60.3 \pm 4.87$ & $61.45 \pm 5.35$ & $0.481^{\mathrm{NS}}$ \\
Mean \pm SD & & & \\
\hline
\end{tabular}


Table (2) Demographic data of infections rate.

\begin{tabular}{|c|c|c|c|c|c|}
\hline & \multicolumn{2}{|c|}{$\begin{array}{c}\text { Supracutenious plate } \\
(\mathrm{n}=20)\end{array}$} & \multicolumn{2}{|c|}{ MIPO Plating $(n=20)$} & \multirow[t]{2}{*}{ P. value } \\
\hline & No. & $\%$ & No. & $\%$ & \\
\hline \multicolumn{6}{|l|}{ Infections } \\
\hline Superficial/pin track. & 5 & 25.00 & 3 & 15.00 & $0.648^{\mathrm{NS}}$ \\
\hline Deep & 1 & 5.00 & 2 & 10.00 & \\
\hline No & 14 & 70.00 & 15 & 75.00 & \\
\hline
\end{tabular}

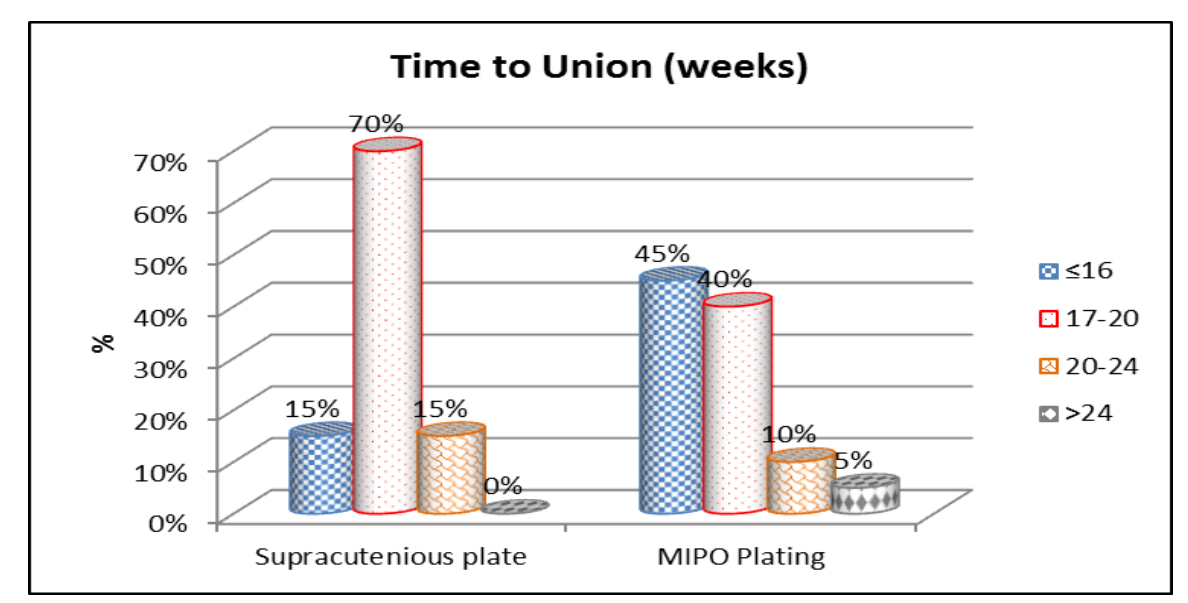

Fig (3) Demographic data of time to union.

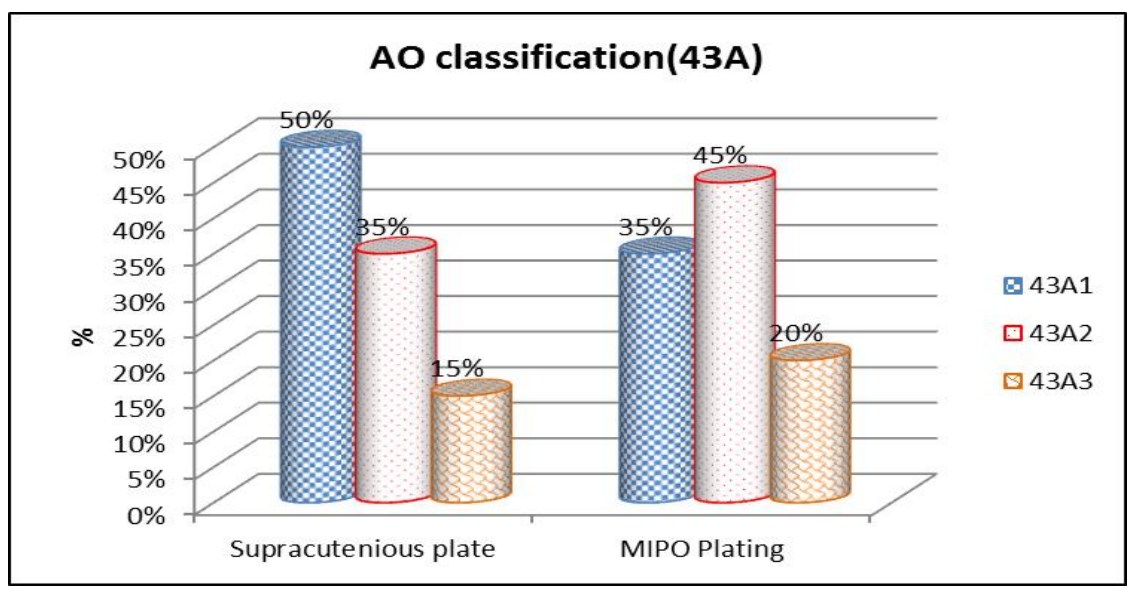

Fig (4) Demographic data of AO classification.

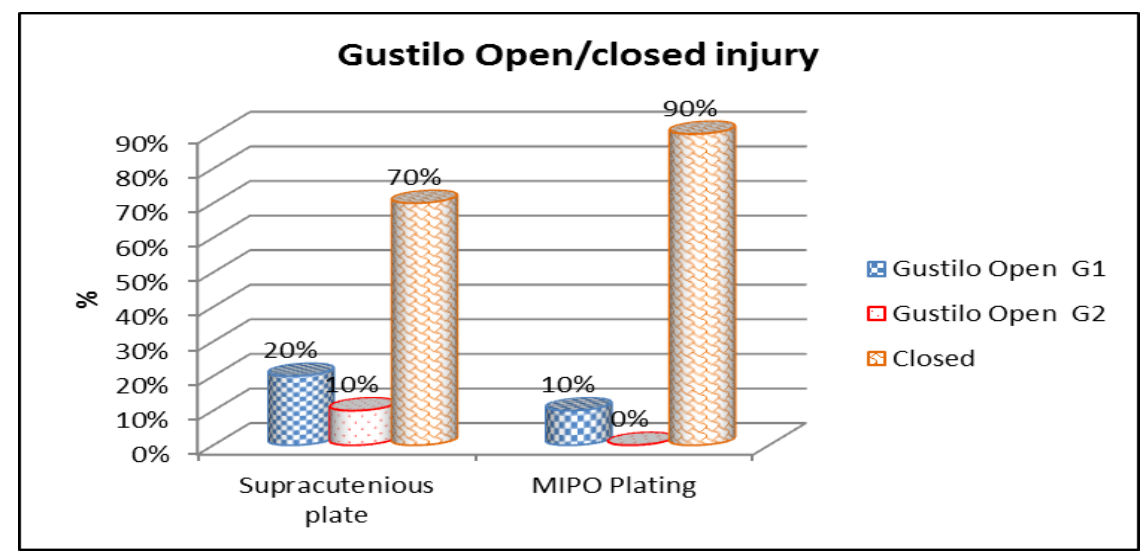

Fig (5) Demographic data of Gustilo Open/closed injury 


\section{Discussion}

Extra articular distal tibial crack, regularly represents a test to the specialist as status of delicate tissue and level of comminution itself muddles the arrangement of the board. The objective of employable treatment is to get anatomical arrangement of the joint surface while giving enough soundness to permit early movement, the encompassing delicate tissues are regularly harmed; in this manner, a treatment that regards these tissues is very important $[14,15]$.

A total decrease of the break could be acquired with an anatomical plating, that require enormous entry points and, in this manner, a danger of high pace of Infection, delicate tissue harm and danger of compartment disorder [15].

This ought to be cultivated utilizing strategies that limit rigid and delicate tissue devascularization with expectations of diminishing the inconveniences coming about because of treatment [16].

At present, the principle surgeries for the treatment of tibial distal cracks are intramedullary nails, bolted plates and outer obsession [17, 18].

Non-association and contamination in cracks of distal tibia is a regularly experienced situation which can be stayed away from by outer adjustment gadgets. A large portion of the outer fixator outlines utilized in lower tibial obsession are massive and awkward to the patient, However, Locking pressure plates as an outside gadget is predominant and beneficial than standard and round outer edges in light of the way that [19] .

1- There are less propensities for the casing to strike the contra parallel appendage during ambulation.

2- Removal of equipment is done under nearby sedation.

3- Provides less obvious outline for imaging permitting simplicity of recuperating evaluation.

4- Small hub miniaturized scale movement diminishes pressure protecting at crack site.

5- Controlled dynamization by evacuating screws is conceivable meddling burden sharing procedure.

6- Multiple screw openings gives greater solidness contrasted with standard pivotal outer fixator.

\section{Certain complexities emerging from utilization of plate as}

1- During utilization of plate as outer fixator both plate and bone sections move freely making exact screw position troublesome.
2- Construct doesn't give improved dependability if locking screws are not put bicortical.

With the advancement of insignificantly obtrusive medical procedure, percutaneous bolted plate structures go about as fixed-point gadgets whose security is given by the hub and precise strength at the screw-plate interface as opposed to depending on the frictional power between the plate and bone, which is thought to save the periosteal blood gracefully around the break site [20,21].

A few investigations were completed to contrast intramedullary nailing with plating, plating to standard and round outer casing and intramedullary nailing to outside fixation [22].

The point of our examination was to look at LCP as an outer gadget (supracutaneous plate) to insignificantly intrusive plate medical procedure (Mipo strategy).

In this examination most basic reason for these cracks was street auto collision (R.T.A) trailed by fall and sports injury particularly football

In this examination, the normal opportunity to association was 18.7 weeks.

In supracutaneous plate strategy, this is equivalent with different reports of percutaneous tibia plating [14]. Anonassociation pace of $5 \%-13 \%$ had been noted by different creators in this procedure of Obsession contrasted with $20 \%$ as in traditional outside obsession [23].

In bunch 1; five patients had releasing discharge around screws (pin track contamination), rewarded by a course of antiinfection agents , and one of them had late profound disease (releasing sinus from injury of open crack), was overseen by debridement and anti-microbials, with frequency of profound disease 5\% and complete contamination $(30 \%)$.

In bunch 11; three patients had shallow contamination, introduced as cellulitis They were treated by a course of anti-infection agents for multi week, and tow persistent had releasing sinus at distal leg with serious consistent agony and growing in leg (profound disease), them two were Gustilo Open G1 (one was overseen by debridement and anti-toxins, the other oversaw by plate expulsion and debridement), with frequency of profound disease $10 \%$ and all out contamination $25 \%$. In certain written works, the pace of disease of plating ranges from $0 \%-6 \%[20,24]$.

The Lower Extremity Functional Scale is $74.87 \%$ in supracutaneous plate bunch 1 with mean $(60.3 \pm 4.87)$. What's more, $75.93 \%$ in 
Mipo bunch 11 with mean $(60.3 \pm 4.87)$.with no measurably centrality, (P. esteem is 0.481 ).

These outcomes emphatically recommends that supracutaneous plate and MIPO procedure treatment are practically identical medicines while thinking about useful result for distal tibial cracks.

This examination results show a predominance of supracutaneous plate over MIPO procedure as far as evacuated after association with easiest expulsion, lower paces of profound diseases and shorter opportunity to full weight bearing. Though MIPO procedure gave off an impression of being worthwhile over supracutaneous plate as far as prompting a superior anatomical and fixed decreases of the crack and a lower pace of association complexities. Embed impingement or distress around the average tibial shin locale is a fundamental whine in Mipo procedure (a cumbersome plate over the average tibial cortex, and uneasiness over the proximal finish of plate).

\section{References}

[1] C.Krettek, S.Bachmann. Pilon fractures. Part 1: Diagnostics, treatment strategies and approaches. Der Chirurg; Zeitschrift fur alle Gebiete der operativen Medizen, Vol.86(1), PP.87-101; quiz 2-4,2015.

[2] R.Gay, J.Evrard. RECENT FRACTURES OF THE TIBIAL PESTLE IN ADULTS. Revue de chirurgie orthopedique et reparatrice de l'appareil moteur, Vol.49, PP.397-512,1963.

[3] H.A.Vallier, T.T.Le, A.Bedi. Radiographic and clinical comparisons of distal tibia shaft fractures (4 to $11 \mathrm{~cm}$ proximal to the plafond): plating versus intramedullary nailing. Journal of orthopaedic trauma, Vol.22(5), PP.30711,2008.

[4] C.Court-Brown, J.McBirnie. The epidemiology of tibial fractures. The Journal of Bone and Joint Surgery British volume, Vol.77(3), PP.417-21,1995.

[5] D.P.Green. Rockwood and Green's fractures in adults: Lippincott Williams \& Wilkins, 2010.

[6] R.Mosheiff, O.Safran, D.Segal. The unreamed tibial nail in the treatment of distal metaphyseal fractures. Injury, Vol.30(2), PP.83-90,1999.

[7] M.Hoenig, F.Gao, J.Kinder. Extraarticular distal tibia fractures: a mechanical evaluation of 4 different treatment methods. Journal of orthopaedic trauma, Vol.24(1), PP.30-5,2010.

[8] I.m.G-I, S-K. Tae. Distal metaphyseal fractures of tibia: a prospective randomized trial of closed reduction and intramedullary nail versus open reduction and plate and screws fixation. Journal of Trauma and Acute Care Surgery, Vol.59(5), PP.1219-23,2005.

[9] D.L.Helfet, P.Y.Shonnard, D.Levine. Minimally invasive plate osteosynthesis of distal fractures of the tibia. Injury, Vol.28, PP.A42-A8, 1997.

[10] M.Blauth, L.Bastian, C.Krettek. Surgical options for the treatment of severe tibial pilon fractures: a study of three techniques. Journal of orthopaedic trauma, Vol.15(3), PP.153-60,2001.

[11]P.Joveniaux, X.Ohl, A.Harisboure. Distal tibia fractures: management and complications of 101 cases. Int Orthop, Vol.34(4), PP.583-8,2010.

[12]D.L.Helfet, K.Koval, J.Pappas. Intraarticular "pilon" fracture of the tibia. Clinical Orthopaedics and Related Research, Vol.298, PP.221-8,1994.

[13] R.Westerman, K.Porter. Ankle fractures in adults: an overview. Trauma, Vol.9(4), PP.267-72,2007.

[14] S.Qiu X-, H.Yuan, X.Zheng. Locking plate as a definitive external fixator for treating tibial fractures with compromised soft tissue envelop. Archives of orthopaedic and trauma surgery, Vol.134(3), PP.383-8,2014.

[15] A.Mudgal, A.K.Daolagupu, V.Agarwala. Management of fractures of the extra articular distal tibia by minimally invasive plate Osteosynthesis-A prospective series of 21 patients. International Journal of Medical Research \& Health Sciences, Vol.5(6), PP.276-82,2016

[16] M.Bisaccia, A.Cappiello.Meccariello L, Rinonapoli G, Falzarano G, Medici A, et al. Nail or plate in the management of distal extra-articular tibial fracture, what is better? Valutation of outcomes. Sicot-j, Vol. 4,2018.

[17] S.V.Gupta, S.P. Parimala.Supracutaneous Locking Compression Plate for Grade I \& II Compound Fracture Distal Tibia-A Case Series, 2013.

[18]R.Frigg. Locking compression plate (LCP). An osteosynthesis plate based on the dynamic compression plate and the point contact fixator (PC-Fix). Injury. 2001;32:63-6.

[19] K.W.Janssen, J.Biert, A.van Kampen. Treatment of distal tibial fractures: plate versus nail. International orthopaedics, Vol.31(5), PP.709-14,2007.

[20] S-W.Yang, H-M.Tzeng, Y-J.Chou.Teng H-P, Liu H-H, Wong C-Y. Treatment of distal tibial metaphyseal fractures: plating 
versus shortened intramedullary nailing. Injury, Vol.37(6), PP.531-5,2006.

[21] C.Krettek, P.Schandelmaier, T.Nliclau. Tscherne H. Minimally invasive percutaneous plate osteosynthesis (MIPPO) using the DCS in proximal and distal femoral fractures. Injury, Vol.28, PP.A20-A30,1997.

[22] T.Borg, S.Larsson, U.Lindsjö. Percutaneous plating of distal tibial fractures: preliminary results in 21 patients. Injury, Vol. 35(6), PP.60814,2004.
[23] V.Pai, G.Coulter, V.Pai. Minimally invasive plate fixation of the tibia. International orthopaedics, Vol.31(4), PP.491-6,2007.

[24] T.H.Williams, W.Schenk. Bridgingminimally invasive locking plate osteosynthesis (Bridging-MILPO): technique description with prospective series of 20 tibial fractures. Injury, Vol.39(10), PP.1198-203,2008. 